\title{
INFLUENCE OF NON-DIPOLE FIELD ON DETERMINATION OF PLIO-PLEISTOCENE TRUE POLAR WANDER
}

David A. Schneider and Dennis $\nabla$. Rent

Lamont-Doherty Geological Observatory and Department of Geological Sciences, Columbia Oniversity

Abstract. Some studies of global paleomagnetic data have found an offset of the magnetic pole during the Plio-Pleistocene which has been interpreted as indicating a period of rapid True Polar Wander, with a rate of movement comparable to the present-day rate of polar motion deduced from astronomical observations. We show that much of the polar offset determined from the paleomagnetic data may be due to deviations in pole position caused by persistent non-dipole zonal components of the geomagnetic field. A correction of paleomagnetic poles for the long-term non-dipole field reduces the polar offset and thus suggests a lower or shorter episode of True Polar Wander over the past 5 million years.

\section{Introduction}

Astronomical observations show that the surface of the Earth has moved some 8 meters relative to the spin axis over the past seventy five years [Dickman, 1979]. The rate for this motion ( $1^{\circ}$ per million years) outpaces the current relative motions of nearly all lithospheric plates [Minster and Jordan, 1978], but it is not clear whether this movement has pergisted long enough for substantial polar motion to accumulate. The geologic evidence for this motion, termed True Polar Wander (TPW), grows from the observation that 8 lobal paleomagnetic data give average magnetic poles which are displaced from the spin axis when plate motions are taken into account [Morgan 1981, Andrews 1985]. Since the time-averaged magnetic field should have no preferred orientation away from the rotation axis, this disagreement has been taken as evidence for TPW. Morgan [1981] and Andrews [1985] report a rapid episode of $T P W$ in the Plio-Pleistocene, accumulating almost $1^{\circ}$ of offset per million years. This implies that the astronomically derived rate has persisted for approximately 5 million years.

We suggest that the Plio-Pleistocene rate of TPW has not been as rapid as supposed. An accurate model of the time-averaged field is required to connect each measurement of the paleo-field with a corresponding pole position. Though her analysis uses the geocentric axial dipole assumption, Andrews [1985] notes that the long-term non-dipole components of the field might be important. We show here that this concern is justified.

\section{Method}

In addition to giving the large offset $\left(4.3^{\circ}\right.$ at $5 \mathrm{Ma}$ ) proposed by Andrews [1985], the

Copyright 1986 by the American Geophysical Union.

Paper number 6L6073

0094-8276/86/006L-6073\$03.00

paleomagnetic data for the past 7 million years were chosen for detailed reanalysis for the effects of the non-dipole field (NDF) because:

1) the offset is based on a large data set ( $N$ $=107$ poles at $5 \mathrm{Ma} ; \mathrm{N}=176$ poles at $1 \mathrm{Ma}$ ),

2) NDF coefficients are relatively well determined for this interval,

3) uncertainties in plate and hotspot motions should have only a small effect on the analysis.

The conventiona 1 determination of paleomagnetic pole position assumes a geocentric axial dipole. Accordingly, paleo-colatitude $(\theta)$, the angular distance between the sampling site and the pole, is determined using

$$
\text { Tan } I=2 \operatorname{Cotan} \theta
$$

where $I$ is the observed inclination of magnetization. The presence of substantial zonal quadrupole (G2) and octupole (G3) components, expressed as a ratio of their Gauss coefficient to that for the geocentric axisl dipole:

$$
\mathrm{G} 2=\mathrm{g}_{2}^{0} / \mathrm{g}_{1}^{0}
$$

and

$$
G 3=g_{3}^{o} / g_{1}^{o}
$$

requires the more cumbersome relation,

$\operatorname{Tan} I=$

$$
\frac{2 \operatorname{Cos} \theta+G 2\left((9 / 2) \cos ^{2} \theta-3 / 2\right)+G 3\left(10 \operatorname{Cos}^{3} \theta-6 \operatorname{Cos} \theta\right)}{\operatorname{Sin} \theta+G 2(3 \operatorname{Sin} \theta \operatorname{Cos} \theta)+G 3\left((15 / 2) \operatorname{Sin} \theta \operatorname{Cos}^{2} \theta-(3 / 2) \operatorname{Sin} \theta\right)}
$$

[Livermore, Vine, and Smith, 1983]. As colatitude is an unknow, this expression must be solved numerically.

In this analysis we use precisely the same Plio-Pleistocene pole positions compiled by

\begin{tabular}{|c|c|c|c|}
\hline Source & Data Set & G2 & G3 \\
\hline $\begin{array}{l}\text { Livermore, } \\
\text { Vine, Smith } \\
\text { [1983] }\end{array}$ & $\begin{array}{l}0-2 \mathrm{Ma} \\
2-6 \mathrm{Ma}\end{array}$ & $\begin{array}{l}.047 \\
.042\end{array}$ & $\begin{array}{l}.013 \\
.027\end{array}$ \\
\hline $\begin{array}{l}\text { Coupland, } \\
\text { Van der Voo } \\
\text { [1980] }\end{array}$ & $\begin{array}{l}0-2 \mathrm{Ma} \\
2-7 \mathrm{Ma}\end{array}$ & $\begin{array}{l}.063 \\
.092\end{array}$ & $\begin{array}{l}.047 \\
.020\end{array}$ \\
\hline $\begin{array}{l}\text { Merril1, } \\
\text { McE1hinny } \\
\text { [1977] }\end{array}$ & $\begin{array}{l}0-5 \mathrm{Ma} \text { (Norm.) } \\
0-5 \mathrm{Ma} \text { (Rev.) } \\
0-5 \mathrm{Ma} \text { (Ave.R+N) }\end{array}$ & $\begin{array}{l}.050 \\
.083 \\
.067\end{array}$ & $\begin{array}{l}.017 * \\
.034 * \\
.026\end{array}$ \\
\hline
\end{tabular}
Andrews [1985] (nomina 1 and $5 \mathrm{Ma}$ sets) to determine magnetization directions. We determine paleo-colatitude using (2) with the NDF

TABLE 1. Representative NDF coefficients

* Sign corrected from original paper. 
TABLE 2. Summary of results of NDF corrections

\begin{tabular}{|c|c|c|c|c|c|c|c|}
\hline Data Set & $\mathbf{N}$ & $\begin{array}{c}\text { Mean } \\
\text { Lat }(N)\end{array}$ & $\begin{array}{l}\text { Pole Posi } \\
\text { Lon(E) }\end{array}$ & $\begin{array}{l}\text { ion } \\
\text { A95 }\end{array}$ & $\begin{array}{c}\text { Corrected } \\
\text { Lat (N) }\end{array}$ & $\begin{array}{l}\text { Pole P } \\
\text { Lon(E) }\end{array}$ & $\begin{array}{l}\text { it ion } \\
\text { A95 }\end{array}$ \\
\hline $\begin{array}{l}1 \text { MY Global } \\
1 \text { MY Globa } 1 \text { (No Rus) } \\
\text { LVS coefficients } \\
\text { MM coefficients }\end{array}$ & $\begin{array}{l}176 \\
118\end{array}$ & $\begin{array}{l}88.5^{\circ} \\
88.4^{\circ}\end{array}$ & $\begin{array}{l}095.0^{\circ} \\
143.5^{\circ}\end{array}$ & $\begin{array}{l}1.4^{\circ} \\
1.5^{\circ}\end{array}$ & $\begin{array}{l}87.5^{\circ} \\
89.1^{\circ} \\
88.8^{\circ} \\
88.9^{\circ}\end{array}$ & $\begin{array}{l}075.8^{\circ} \\
126.9^{\circ} \\
120.7^{\circ} \\
110.7^{\circ}\end{array}$ & $\begin{array}{l}1.4^{\circ} \\
1.4^{\circ} \\
1.4^{\circ} \\
1.3^{\circ}\end{array}$ \\
\hline $\begin{array}{l}5 \text { MY Global } \\
\text { LVS coefficients } \\
\text { MM coefficients } \\
5 \text { MY Global (No Rus) }\end{array}$ & 107 & $85.7^{\circ}$ & $142.0^{\circ}$ & $2.7^{\circ}$ & $\begin{array}{l}87.7^{\circ} \\
87.2^{\circ} \\
87.5^{\circ} \\
87.6^{\circ}\end{array}$ & $\begin{array}{l}158.2^{\circ} \\
175.1^{\circ} \\
165.8^{\circ} \\
095.2^{\circ}\end{array}$ & $\begin{array}{l}1.9^{\circ} \\
1.9^{\circ} \\
1.9^{\circ} \\
2.4^{\circ}\end{array}$ \\
\hline
\end{tabular}

coefficient ratios estimated by Coupland and Van der Voo [1980] from a similar compilation of paleomagnetic data. The two sets of coefficients used here, the quadrupole (G2 =.063 at $1 \mathrm{Ma} ; .092$ at $5 \mathrm{Ma}$ ) and octupole (G3 $=.047$ at $1 \mathrm{Ma} ; .020$ at $5 \mathrm{Ma}$ ), were estimated for time intervals which closely match the divisions used by Andrews [1985] (0-2 Ma for the nominal $1 \mathrm{Ma}$ pole; 3-7 Ma for the nominal $5 \mathrm{Ma}$ pole). These lowest order zonal quadrupole and octupole ratios are the best determined parts of the long-term NDF and, for the purposes of this correction, we treat the NDF estimates as exact. Table 1 gives the range for these values which have been found in several recent spherical harmonic analyses.

We use the corrected paleo-colatitude to recalculate pole positions using rotated site locations given by Andrews [1985] i.e., in the hotspot reference frame. The poles are averaged, using conventional Fisher statistics, both by region and globally following Andrews's [1985] procedure. Table 2 contains our numerical results; $95 \%$ confidence limits are shown in all figures.

\section{The 5 Million Year Pole}

Uncorrected $5 \mathrm{Ma}$ poles, in agreement with Andrewe [1985], produce a near $5^{\circ}$ mean offset

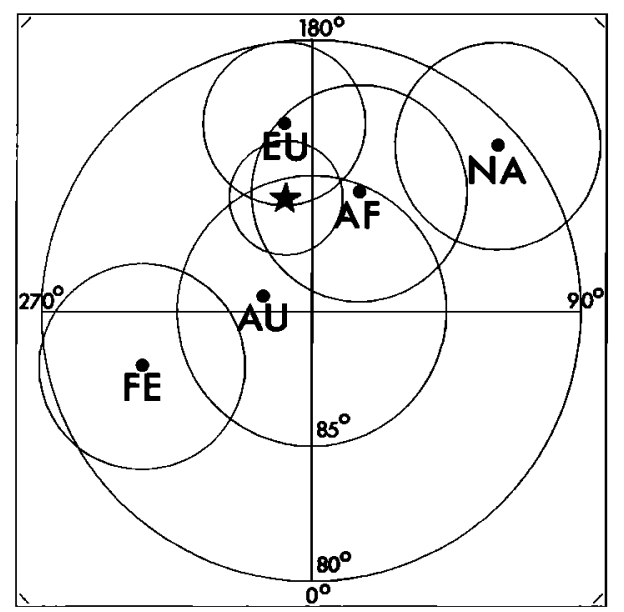

from the rotation axis (Figure 1 left). The regional subsets give poles which clearly show the far-sided effect [Wilson, 1970]: the regional means plot on the far side of the rotation axis with respect to the source areas. The far-sided effect, which Wilson modeled in terms of an offset dipole, is expected from the NDF components described here in terms of spherical harmonics.

Though a uniform site distribution would give uniformly far-sided poles which average to the rotation axis, such an even distribution would be difficult to achieve and is certainly not approached in this compilation which excludes Pacific paleomagnetic data. The lack of (far-sided) Pacific poles thus leaves this important effect uncompensated and we suspect that the global mean is drawn toward the Pacific hemisphere for this reason.

With a non-dipole correction, the far-sided effect is attenuated and the global mean falls $2.3^{\circ}$ from the spin axis (Figure 1 right), which is significant but only about half the magnitude of the offset without the correction.

\section{The 1 Million Year Pole}

Uncorrected poles for the $1 \mathrm{Ma}$ data set, as in the Andrews [1985] analysis, show a significant

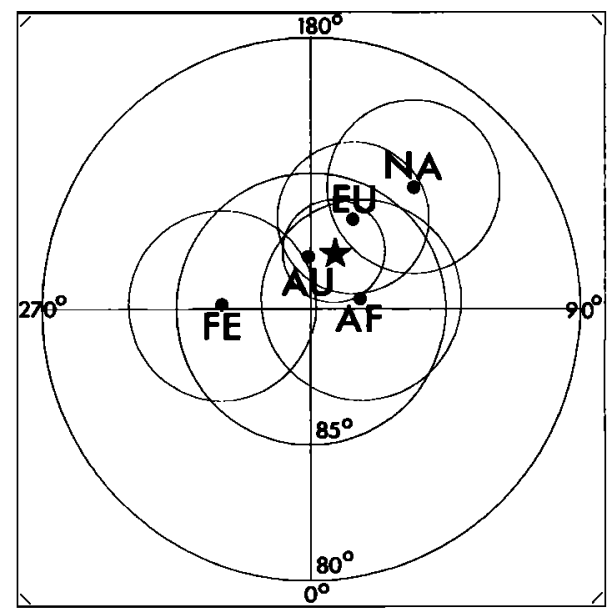

Fig. 1. Global (star) and regional (Africa, AF; Australia, AU; Europe, EU; Far East, FE; North America, NA) mean pole positions with $95 \%$ confidence circles for 5 Ma data set before (left) and after (right) correction for non-dipole fields. (Confidence limit for Australian pole falls off scale.) 

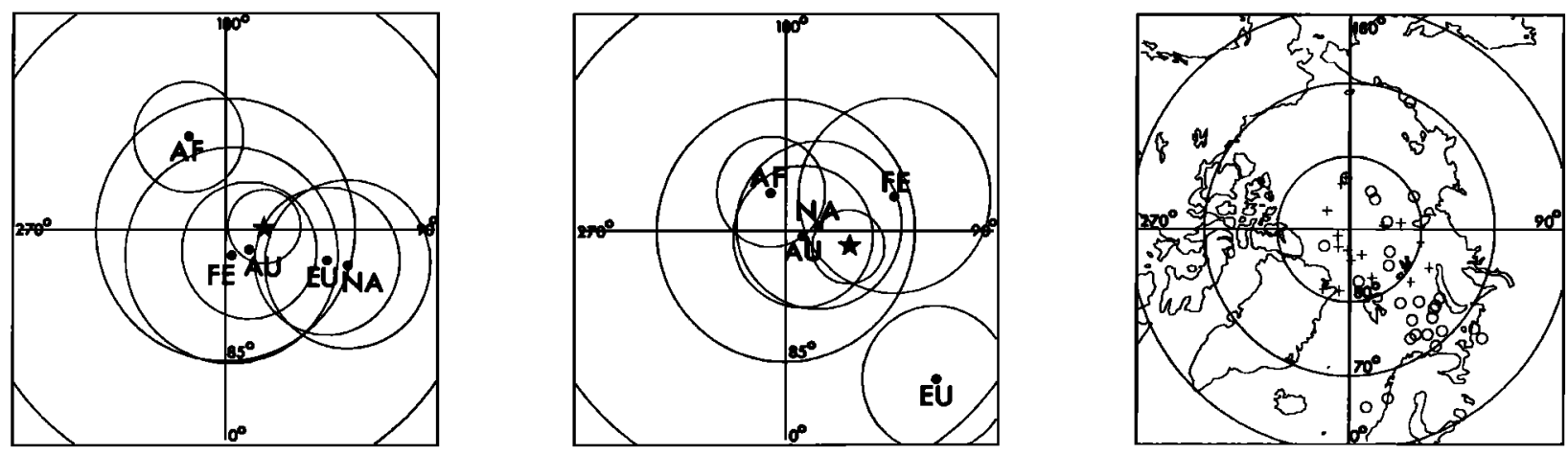

Fig. 2. Global and regional mean pole positions for $1 \mathrm{Ma}$ data set before (left) and after (center) correction for non-dipole fields. Conventions as in Figure 1. Individual European poles after correction for non-dipole fields with Russian poles shown as open circles (right).

$\left(1.5^{\circ}\right)$ offset between the mean paleomagnetic pole and the rotation axis (Figure 2 left). Here however, the far-sided effect is less clear and in particular the so-called European poles are near-sided.

The non-dipole correction (Figure 2 center) gives regional poles which better coincide, except that the European mean shows a distinctly different direction, more than $8^{\circ}$ from the rotation axis.

The inconsistency in location of the European regional pole indicates that there may be problems with the quality of at least this portion of the data set. Figure 2 right shows the individual European pole locations (corrected for the NDF) with Russian data shown as open circles. Many of the Russian poles plot over $15^{\circ}$ from the spin axis, casting doubt on their reliability.

The removal of Russian data (from both Europe and the Far East) improves the Fisher precision parameter of the global average at the $99 \%$ confidence level indicating that the Russian pole determinations contained in the $1 \mathrm{Ma}$ set are of poor quality. As the mean of the Russian poles $\left(83.2 \mathrm{~N}, 63.8 \mathrm{E}, \mathrm{A95}=3.1^{\circ}\right)$ is distinct from the mean of the remaining $1 \mathrm{Ma}$ poles, these $1 \mathrm{Ma}$ Russian data are excluded from further analysis.
The edited data set (Figure 3 left) shows the far-sided effect more clearly and, as with the 5 Ma case, the mean is displaced toward the Pacific hemisphere. Upon correction for the NDF (Figure 3 right), the regional poles cluster and the offret in the global mean is reduced to $.9^{\circ}$ which is statistically indistinguishable from the rotation axis.

\section{P1io-Pleistocene True Polar Wander}

The corrected poles (Figure 4) suggest a trend in TPW; however, the indicated rate over the past 5 million years is less than $1 / 2$ the astronomically derived rate of $1^{\circ}$ per million years. The correction for the NDF has reduced the magnitude of the offset over the past 5 million years so that it is difficult to determine whether TPW has operated uniformly over this period and whether the suggested trend is significant.

The 1 and $5 \mathrm{Ma}$ poles change only slightly (less than $.9^{\circ}$ in global means) when calculated using the two alternate sets of NDF coefficients in Table 1, so that the choice of these values does not appear to be very critical. Nor are the results much affected by the plate motion hotspot model as the $5 \mathrm{Ma}$ pole determined with no plate
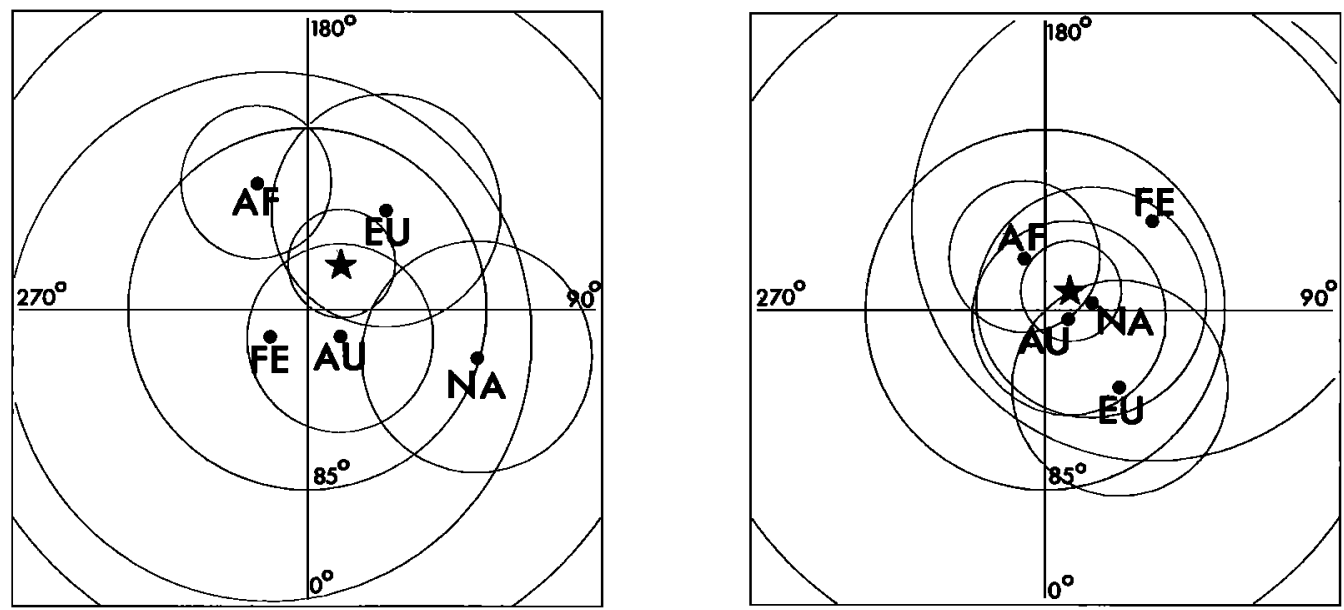

Fig. 3. Global and regional means for $1 \mathrm{Ma}$ set, with Russian poles removed, before (left) and after (right) correction for non-dipole fields. Conventions as in Figure 1. 


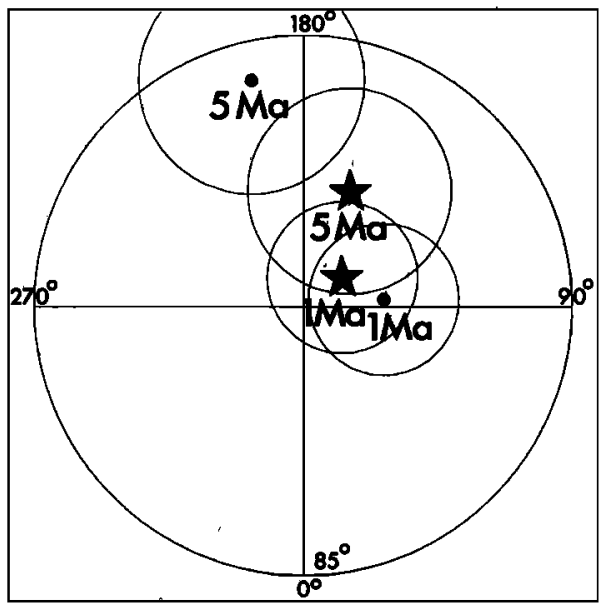

Fig. 4. Global mean poles for $1 \mathrm{Ma}$ (without Russian data) and $5 \mathrm{Ma}$, before (dot) and after (star) correction for non-dipole fields.

rotations $\left(87.6 \mathrm{~N}, 162.7 \mathrm{E}, \mathrm{A} 95=1.9^{\circ}\right)$ is changed only by $.2^{\circ}$.

There is however a great sensitivity of results to the composition of the dats set as illustrated by the $2.1^{\circ}$ change in the $1 \mathrm{Ma}$ mean with removal of Russian poles. Thus the sigrificance of the small offsets which remain after the NDF correction depends strongly on such judgements about the data. We minimized our manipulations, removing Russian poles to give consistent results in the $1 \mathrm{Ma}$ case, though other choices are possible and do alter the resulting mean pole positions. For instance, restoration of Rusisian data in the Far East group gives a 1 Ma pole at $88.4 \mathrm{~N}, 112.1 \mathrm{E}\left(\mathrm{A95}=1.4^{\circ}\right)$ which is significantly different from the rotation axis. Removal of Russian poles from the $5 \mathrm{Ma}$ set changes the mean to $87.6 \mathrm{~N}, 95.2 \mathrm{E}$, altering the direction if not the magnitude of the suggested TPW trend.

Removing Russian poles orily from the $1 \mathrm{Ma}$ set gives corrected mean poles which are in good agreement with the best fitting dipole directions of Livermore, Vine and Smith [1983] as determined by their spherical harmonic analysis of paleomagnetic data. They did not consider the small off set in their 2-6 Ma pole (of $1^{\circ}$ to $2^{\circ}$ ) to be ignificant; the $2.3^{\circ}$ of feet found here for the $5 \mathrm{Ma}$ pole is but marginally 80 . Indeed they [Iivermore, Vine, and Swith, 1984] ouggest there has been little relative motion between the hotspot and geomagnetic reference frames during the past $90 \mathrm{Ma}$.

As the revised 1 and $5 \mathrm{Ma}$ paleomagnetic poles cannot be showh to be distinct, our results do not exclude the possibility that Plio-Pleistocene TPW has occurred only in about the last million years. If this is the case, then the best estimate of the magnitude of such TPW is given by averaging the 1 and $5 \mathrm{Ma}$ sets as one population, which gives a pole at $88.5 \mathrm{~N}, 149.0 \mathrm{E}\left(\mathrm{A} 95=1.1^{\circ}\right)$. This possibility is consistent in timing with the argument that Pleistocene glaciation is a potent driving mechanism for TPW [Sabadini, Yuen and Boschi 1982] though the direction found here suggests $1.5^{\circ}$ movement of the spin axis toward Greenland and Nortb America, rather than away from such areas of glaciation as modeled by Sabadini et al.

This analysis demonstrates that non-dipole fields mut be considered and treated in evaluating small differences in pole position. The significance of the residual offsets after correction for the WDF then depends largely on judgements about the data set. Thus even more numerous and higher quality paleomagnetic dats will be needed to fully confirm or deny the small amount of P1io-Pleistocene TPW suggested by these results.

Acknowledgments. We wish to thank Jean Andrews for generously providing us access to her data compilation as well as Steven Cande and Dan Davis for reviewing the manuscript. Work supported by NSP Oceanography grant OCE84-00805.

Lamont-Doherty Geological Observatory contribution $\$ 3971$.

\section{References}

Andrews, J.A., True polar wander: an analysis of Cenozoic and Mesozoic paleomagnetic poles, J. Ceophys. Res.., 90, 7737-7750, 1985.

Coupland, D.H., and R. Van der Voo, Long-term nondipole componente in the geomagnetic field during the last 130 M.Y., J. Geophys. Res.. 85, 3529-3548, 1980.

Dickman, S.R., Continental drift and true polar vander, Geophys, J. R. Astr. Soc.. 57, 41-50, 1979.

Livermore R.A., F.J. Vine, and A.G. Smith, Plate motions and the geomagnetic Field - I. Quaternary and late Tertiary, Geophys. J. R. Astr. Soc.s 73, 153-171, 1983.

Liverwore R.A., F.J. Vine, and A.G. Smith, Plate motions and the geomagnetic Field - II. Jurassic to Tertiary, Geophys, J. R. Astr. Soc.. 79, 939-961, 1984.

Merrill, R.T., and M.W. McElhinny, Anomalies in the time-averaged paleomagnetic field and their implications for the lower mantle, Rev. Geophys. Space Physic8, 15, 309-323, 1977.

Minster, J.B., and T.B. Jordan, Present-day plate motions, J. Geophy8. Res., 83. 5331-5354, 1978.

Morgan, W.J., Hotspot tracks and the opening of the At lantic and Indian Oceans, in The Sea, I. edited by C. Imiliani, pp. 443-487, Wiley, New York, 1981

Sabadini, R., D.A. Yuen, and E. Boschi, Polar wandering and the forced responses of a rotating multilayered viscoelastic planet, J. Geophys. Res.e 87, 2885-2903, 1982.

Wilson, R.T., Permanent aspects of the earth's non-dipole magnetic field over the past 25 million years, Geophys. J. R. Astr. Soc.. 22, $417-437,1970$.

D.A. Schneider and D.V. Rent, Lamont-Doherty Geological Observatory, Palisades, NY 10964.

(Received February 21, 1986; accepted March 26, 1986.) 